\title{
THE EFFECT OF ENVIRONMENTAL AND HUMAN FACTORS ON THE DISTRIBUTION OF BROWN BEAR (URSUS ARCTOS ISABELLINUS) IN IRAN
}

\author{
HOSSEINI, S. P. ${ }^{*}-$ AMIRI, M. $^{2}-$ SENN, J. ${ }^{3}$ \\ ${ }^{1}$ Range and Watershed Management Department, Natural Resources Faculty, Isfahan \\ University of Technology, Isfahan, Iran \\ (e-mail: seyedpouyahosseini@gmail.com; phone: +98-918-999-6289) \\ ${ }^{2}$ Natural Resources Department, University of Applied Science and Technology (UAST), Branch \\ of Mazandaran, Wood and Paper Industries, Sari, Iran \\ (e-mail: mohaddesehamiri@yahoo.com; phone: +98-936-731-1969) \\ ${ }^{3}$ Swiss Federal Institute for Forest, Snow and Landscape Research, WSL, Zurich, Switzerland \\ (e-mail: Josef.senn@wsl.ch; phone:+41-447-392-381) \\ "Corresponding author \\ e-mail: seyedpouyahosseini@gmail.com; phone: +98-918-999-6289 \\ (Received $15^{\text {th }}$ Jun 2021; accepted $28^{\text {th }}$ Oct 2021)
}

\begin{abstract}
Brown bear (Ursus arctos isabellinus) in Kurdistan Province of Iran is considered as a regionally threatened species. Therefore, understanding spatial distribution of brown bear and influencing factors is fundamental to their conservation. In this study, occurrence records of brown bear coupled with environmental and habitat data were compiled, and suitable habitats of this species was predicted through five species distribution models (SDMs) including Random Forest (RF), Classification Tree Analysis (CTA), Artificial Neural Network (ANN), Generalized Linear Model (GLM), Maximum Entropy (MaxEnt), as well as an ensemble approach. To evaluate each model's predictive performance, area under the curve (AUC) and true skill statistic (TSS) were measured. All models showed AUC values higher than 0.9 under scenario I, indicating excellent overall prediction accuracy. The accuracy statistics derived by the ensemble maps were higher than those derived by single SDMs. Among the single models, GLM and MaxEnt scored the highest partial AUC values under both scenarios. Temperature seasonality, isothermality, precipitation of the driest month, and distance to village were recognized as the most effective variables in predicting suitable habitats for brown bear. Our findings demonstrated the usefulness of the ensemble approach and the high accuracy of GLM and MaxEnt in the species distribution modelling. Keywords: bioclimatic variables, habitat suitability modelling, human-bear conflict, ensemble, conservation, Zagros Forests
\end{abstract}

\section{Introduction}

Large carnivores like brown bears (Ursus arctos isabellinus, Linnaeus 1758) are highly susceptible to habitat loss and fragmentation caused by human activities (Zanin et al., 2015), climate change (Rodriguez et al., 2007), and are in priority for conservation, as assuring the needs of these umbrella species also helps in protecting other species (Beier et al., 2008). Brown bear as the biggest carnivore in Iran is an important species and is found in the north, west, and north-west of the country and across the Alborz and Zagros mountain ranges. During the last decades and due to the deforestation and heavy harvesting of non-timber products in the Zagros Forests, brown bear has become highly endangered (Gutleb and Ziaie, 1999); and this species is officially placed in the list of threatened species in many regions (McLellan et al., 2016). The presence of brown bear may also be used as an indicator for healthy ecosystems supporting natural ecological 
processes and species interaction little affected by human presence and intervention (Yousefi, 2016). Predicting potential habitat beyond the present range is an essential step towards proactive management strategies minimizing human-wildlife conflict, thereby promoting large carnivore population viability in the future (Treves et al., 2004).

Species distribution models (SDMs) are an important tool for studying basic questions regarding the potentially suitable habitat for species and their environmental determinants and are used for many purposes in biogeography, conservation and ecology (Elith and Leathwick, 2009). Over the last decades, several algorithms have been developed to model species distributions (Thuiller et al., 2009). Some studies have suggested that the accuracy of species distribution predictions could be substantially improved by applying consensus methods (Thuiller et al., 2009; Araújo et al., 2011).

The Zagros Forests cover an area of about six million hectares and account for around $45 \%$ of Iran's forests. The Zagros Forests provide home for approximately $10 \%$ of Iran's human population (Department of Environment, 2014). These forests are recognized as pastoral ecosystems, which for thousands of years have been exposed to grazing by livestock influencing the structure and function of the forest (Hoekstra and Shachak, 1999). The Zagros Forests are made up of northern and southern main divisions. In the northern division due to the special economic and social situations, people are dependent on the forests in many aspects, including non-timber product harvesting and cultivation of crops under the forest canopy resulting in forest degradation. Further, local communities traditionally coppice trees for fodder for livestock in winter (Ghazanfari, 2003; Henareh-Khalyani et al., 2014). Additionally, the Zagros Forests have lately been influenced by intensive drought (Arsalani et al., 2015); and fungal pathogen outbreaks, leading to a gradual dieback of the oak forests (Mirabolfathy et al., 2011). Habitat degradation especially due to agricultural expansion and intensification leads to conflicts between brown bear and humans (Can et al., 2014).

There are three central objectives of this study: 1) identifying brown bear habitat and propose priority regions for conservation programs and areas for the protection of the species in Kurdistan Province, 2) identifying anthropogenic and environmental parameters affecting habitat suitability and distribution, and 3) evaluating and comparing the performance of the modelling algorithms and the ensemble approach in species distribution modelling.

\section{Materials and methods}

In the present study, occurrence data was collected and together with additional bioclimatic data and ecological parameters distribution of the species was projected. In continue study area, our approach for collecting data in the field, as well as the approaches used for modelling of the species distribution will be described.

\section{Study area and species}

This study was carried out in Kurdistan Province in the north-west of Iran and along the border with Iraq. Kurdistan is a mountainous province covering an area of about $29048 \mathrm{~km}^{2}$ and includes the Zagros oak-dominated forests. These forests are home to many mammals including brown bear (Ziaie, 2008); and plants like Quercus spp. (oaks), Pistacia mutica (wild pistachio), Crategus spp. and Pyrus spp. (Jazirehi and Rostaghi, 2003). The northern part of the Zagros Forests is an exclusive habitat for $Q$. infectoria associated with $Q$. libani or $Q$. brantii or both of them, while, the southern part of the 
forests is dominated by $Q$. brantii (Sagheb-Talebi et al., 2003). The Zagros Mountain Range thanks to their height and longitude receive precipitation from air masses coming from the Persian Gulf and the Mediterranean Sea in the west. The western part of the Iranian plateau in the mid-Zagros range experiences a pronounced seasonal change in precipitation and temperature (Sharifi et al., 2009). The northern part of the Zagros Forests is wetter and cooler than the southern part (Sagheb-Talebi et al., 2003). The average precipitation of Kurdistan Province accounts for $517 \mathrm{~mm}$ with maximum precipitation of $990 \mathrm{~mm}$ in the west of the province and the average temperature varies from 7 to $14{ }^{\circ} \mathrm{C}$ (Hanafi and Hatammi, 2013). In the study area (Fig. 1), the altitude ranges from 740 meters to 3161 meters above sea level. In the western part of the Zagros Mountain Range many seasonal and perennial rivers are fed by the snow accumulated in winter at the higher altitudes (Sharifi et al., 2009). The main stream is Sirwan River running through Shaho-Kosalan and flowing into Daryan Dam in the south-west of the study area.
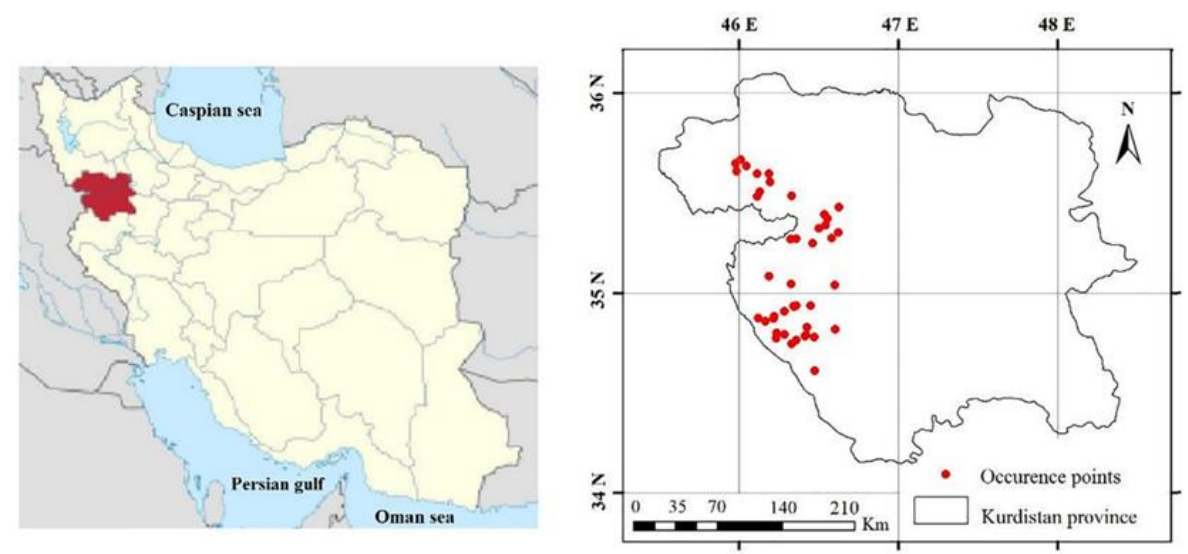

Figure 1. Map of Iran and Kurdistan Province (left) and the brown bear's occurrence points in Kurdistan Province (right)

Brown bears are opportunistic omnivores that rapidly learn to use new food sources once they become available. Food availability is a determining factor in the distribution and home range of bears (Hwang et al., 2010). Gutleb et al. (2002) estimated population of this species in the Zagros Forests fewer than one hundred and found these forests as relatively poor habitats for the species. Brown bears prefer densely forested areas (Kobler and Adamic, 2000); and feed on a wide range of foods including green vegetation, such as graminoids, forbs, and fruits in springs and early summer depending on the availability. In autumn and winter, brown bears forage on tree masts like acorns (Quercus) and chestnuts (Castanea sativa) (Swenson et al., 2000). Brown bear is an important disperser of seeds as it may swallow large amounts of fruits and seeds (Welch et al., 1997); and usually travels over long ranges, spreading seeds far away from the origin. There is evidence that seed passage through the species digestive tracts may improve germination rates to some degree in a number of plant species (Willson and Gende, 2004); making bears an effective agent for the conservation of certain plant species.

Availability of high energy foods in late summer and autumn is essential for the species hibernation. Brown bears need large continuous areas of habitat and occur in low population densities. They may be active during the day and at night, and their activity 
depends on food, environmental conditions, and human activity (Swenson et al., 2000). Brown bears are considered dangerous to humans and their livestock resulting in conflicts with local human communities, including attacks on humans, damage to human properties and agricultural products, and preying on livestock and domestic animals (Can et al., 2014).

\section{Species occurrence and environmental data}

In this work, a database of brown bear occurrences within Kurdistan Province was used that consists of geo-referenced localities where the species has been observed directly, or recorded damage to livestock, beehives, and crops caused by the species. Additional records from the existing scientific literature and researchers were included, too. Finally, a total of 40 independent records with a minimum distance of one $\mathrm{km}$ between the records were obtained.

Environmental data include multiple remote sensing and other spatial layers such as bioclimatic, physiographic, Normalized Difference Vegetation Index (NDVI), and anthropogenic variables. Climatic variables and variations in precipitation and temperature have a profound effect on species distribution range (Moraitis et al., 2019; Wang et al., 2019). Bioclimatic variables including eleven temperature and eight precipitation factors were collected from the WorldClim database. WorldClim version two has average monthly climate data for minimum, mean, and maximum temperature and for precipitation for 1970-2000 (http://www.worldclim.org). Autocorrelation between input variables could lead to collinearity, overfitting, and misinterpretation of results. In order to detect and exclude highly correlated variables, Pearson's correlation coefficient between each pair of predictors was calculated. In case two variables had a significant correlation coefficient $(-0.7<\mathrm{r}<0)$, one of them that was ecologically more important was selected to be involved in the modelling (Yi et al., 2016) (Table 1).

Table 1. Environmental predictor variables employed for modelling the brown bear distribution and the sources data were derived

\begin{tabular}{c|c|c}
\hline Predictor variables & Description & Source/Reference \\
\hline \multirow{4}{*}{ Climatic } & Bio3 = Isothermality $($ Bio2 $/$ Bio7 $)(\times 100)$ & WorldClim \\
& Bio4 = Temperature Seasonality (standard deviation $\times 100)$ & WorldClim \\
& Bio8 = Mean Temperature of Wettest Quarter $\left({ }^{\circ} \mathrm{C}\right)$ & WorldClim \\
& Bio14 = Precipitation of Driest Month $(\mathrm{mm})$ & WorldClim \\
& Elevation $(\mathrm{m})$ & SRTM DEM data \\
Physiographic & Slope & SRTM DEM data \\
& Aspect & SRTM DEM data \\
& Distance to river $(\mathrm{m})$ & $1 / 25000$ \\
NDVI & NDVI & Topographic map \\
& USGS \\
Anthropogenic & Distance to road $(\mathrm{m})$ & Topographic map \\
& Distance to village $(\mathrm{m})$ & $1 / 25000$ \\
& & Topographic map \\
\hline
\end{tabular}

Physiographic data involves aspect, elevation, slope, and distance to river, and anthropogenic includes distance to village and distance to roads. Using the 90-meter spatial resolution digital elevation model (DEM) from the shuttle radar topography 
mission (SRTM) three topographic explanatory variables including slope, elevation, and aspect were compiled. A topographic map (scale 1:25000) of the study area was employed for the calculation of distance to village, distance to road, and distance to river. NDVI was another variable used in the modelling as an index for greenness, which permitted discrimination of vegetated areas.

Among the vegetation indices that permit discrimination of vegetated areas, NDVI is widely used. NDVI is the difference between the red and near-infrared band combination, divided by the sum of the red and near-infrared band combination (Equation 1). In this study, MODIS-derived NDVI with $1 \mathrm{~km}$ spatial resolution obtained from USGS (United States Geological Survey, 2020) was selected as a remote sensing predictor for mapping distributions. NDVI is calculated as follows:

$$
N D V I=\frac{(\rho N I R-\rho R e d)}{(\rho N I R+\rho R e d)}
$$

where $\rho$ NIR and $\rho$ Red represent the surface reflectance values of the near-infrared and the red wavelengths, respectively. The layers finally were resampled to 30-arc second resolution to be utilized in the modelling process.

\section{Modelling approaches}

Locating suitable habitats as well as determining the most important factors for species distribution are among the most common applications of SDMs (Phillips et al., 2006). Modelling was implemented in the Biomod2 package where it was developed for the $\mathrm{R}$ 4.0.3 statistical-programing software. Ten modelling algorithms are available in this package, of which we used five to evaluate and compare the model's predictability and to develop an ensemble forecasting map for brown bear in the study area and finally to investigate the effects of anthropogenic and environmental variables on the distribution of the species. Modelling algorithms used in this study are briefly introduced in continue.

Generalized Linear Models (GLMs) are a set of parametric methods (McCullagh and Nelder, 1989); allowing more flexible relationships to be specified in terms of many link functions between the response and predictor variables as compared to linear regression models. When response data is binary, the appropriate GLM is a logistic model using a logit link to depict the relationship between the response and the linear sum of the predictor variables (Hosmer and Lemeshow, 2000).

Artificial Neural Network (ANN) techniques are one of the robust rule-based approaches that used in bioclimatic envelope modelling (Berry et al., 2002; Thuiller et al., 2003). Such model is based on the function of the human brain and has been developed to build mathematical models that mimic the computing power of the human brain and has great benefits in different applications (Tripathi, 2015). ANN is composed of primary computational units called neurons combined based on different architectures. For instance, they can be ordered in layers (multi-layer network), or they may have a connection topology. According to Figure 2, layered networks include, 1) input layer, consist of $n$ neurons, 2) hidden layer, made of one or several hidden (intermediate) layer consisting of m neurons, 3) output layer, consisting of p neurons, 4) the feedback and feedforward architecture (feedback architecture has connections between neurons of the same or previous layer, but feedforward architecture does not have any feedback connections) (Gallo, 2015). 


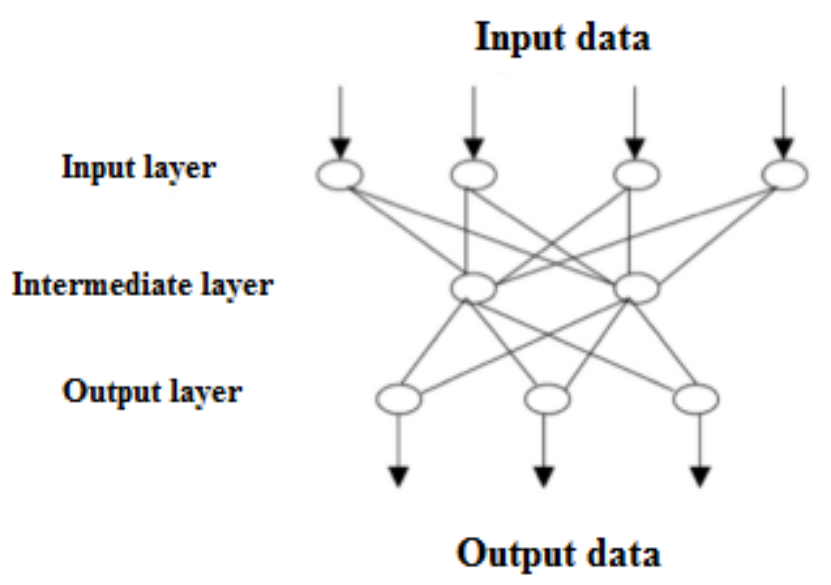

Figure 2. A simple structure of an artificial neural network (ANN) with input, hidden (intermediate) and output layers

Random Forest (RF) in performance is one of the most accurate classificatory regression tree-based models. In RF, bootstrap aggregation is used to select many subsamples from the data, generated through a bagging algorithm, a large number of decorrelated regression trees. RF tree predictors are combined in a way that each is dependent on the values of independently sampled random vectors, assuming similar distribution for each tree in the forest (Breiman, 2001).

Classification Tree Analysis (CTA) is a supervised non-parametric statistical classification approach based on binary recursive partitioning techniques. In CTA, a binary decision (True or False) is made by considering only one of the environmental parameters at each node of the tree. Then the node divides a class into two different subclasses whose purity level increases (Breiman et al., 1984; De'Ath, 2007).

Maximum Entropy (MaxEnt) is a machine learning program based on maximum entropy that estimates the probability distribution for species occurrence based on environmental constraints. It requires species presence data only (not absence) and environmental variable (continuous or categorical) layers for the study area (Phillips et al., 2006). MaxEnt is known as one of the most accurate methods used most extensively for predicting the geographical distribution of animal and plant species (Phillips et al., 2006, 2009).

The ensemble map represents the averaging of the projections made by different models (Marmion et al., 2009). The ensemble approach decreases the uncertainty of each model predictions by simultaneous assessment of the results obtained by the different models (Araújo and New, 2007; Amiri et al., 2020). The ensemble maps were achieved by combining the binary habitat maps from the five individual models into a single map. In this case, $S e$ which is called 'consensus suitability' in BiodiversityR is calculated as the weighted mean of suitabilities obtained from single models (Si) (Equation 2). This allows obtaining more robust predictions and estimating the variability across techniques (Buisson et al., 2010).

$$
\mathrm{S}_{\mathrm{e}}=\frac{\sum_{\mathrm{i}}^{\mathrm{n}} \mathrm{W}_{\mathrm{i}} \mathrm{S}_{\mathrm{i}}}{\sum_{\mathrm{i}}^{\mathrm{n}} \mathrm{W}_{\mathrm{i}}}
$$


where $S i$ is the probability surface generated by a single model $(i)$; and $W i$ is the weight assigned to a single model ( $i$ ) that was calculated as a ratio of the AUC value of a single model divided by the total AUC values of the five single models (Kindt, 2018).

The employed models required simulated pseudo-absence data on locations where the brown bear is absent. Thus, we randomly generated a collection of pseudo-absence points using the Create Random Point tool in ArcGIS 10.3. In order to create pseudo-absence points not within or near the presence points, a random sampling plan was applied that excluded the buffer zone of $2.5 \mathrm{~km}$ around the presence points.

In the predictive phase of modelling, each of the modelling methods generates an estimate of probability of the species presence ranging from 0 to 1 where 0 stands for the lowest probability and 1 stands for the highest probability corresponding to the probability that a pixel is a favorable habitat for the species. Ranges were then classified into four probability classes using an equal interval classification scheme as follows: low suitability $(0-0.25)$, moderate suitability $(0.25-0.5)$, good suitability $(0.5-0.75)$, and high suitability $(0.75-1)$ to interpret easily.

\section{Modelling evaluation}

Statistical evaluations of SDM predictions have generally been performed through the true skill statistic (TSS) and the area under the receiver operating characteristic (ROC) curve (AUC). AUC plots the accuracy of the predicted presence (sensitivity) against the accuracy of predicted absence (1 - specificity) (Allouche et al., 2006). Sensitivity (Equation 3) is the probability that a model correctly classifies the presence data (positive rate in the positive results) and specificity (Equation 4) represents the probability of classifying correctly the absence data points (negative rate in the negative results) (Ray et al., 2016).

$$
\text { Sensitivity }=\frac{a}{(a+b)}
$$

where $a$ is the number of cells where the models predict presence correctly (true positive) and $b$ is the number of cells in which the species was not found although presence was predicted by the model (false positive; commission error).

$$
\text { Specificity }=\frac{d}{(d+c)}
$$

where $d$ is the number of cells where the models predict absence correctly (true negative) and $c$ denotes the number of cells in which the species was found although absence was predicted by the model (false negative; omission error).

TSS considers both omission and commission errors and varies from -1 to +1 in which +1 exhibits the total agreement and 0 or less denote that the model's predictability is random. TSS values are categorized as follows: $0-0.4=$ failing, $0.4-0.55=$ poor, 0.55 0.7 = fair, $0.7-0.85$ = good, $0.85-1$ = excellent (Allouche et al., 2006) (Equation 5):

$$
T S S=a d-\frac{b c}{(a+c)+(b+d)}=\text { Sensitivity }+ \text { Specificity }
$$

AUC value ranges between 0.5 - 1 in which values around 0.5 show that the model's performance is random and 1 represent a perfect performance. Evaluation criteria for 
AUC are as follows: $0.5-0.6=$ poor, $0.6-0.7=$ fair, $0.7-0.8=\operatorname{good}, 0.8-0.9=$ very good, $0.9-1.0=$ excellent (Swets, 1988).

Variable selection is one of the most biological-based decisions in SDM which helps us to bring the more informative variables into the modelling. Unsuitable variable selection may lead to misleading model projections (Velez-Liendo et al., 2013). Two scenarios, that represent two common approaches to variable selection, were run for the species using different sets of predictor variables and to obtain a potential distribution map with the highest accuracy. In the first scenario bioclimatic variables which are identified as the most widely employed set of variables in SDM (Porfirio et al., 2014) as well as NDVI, and in the second scenario all twenty-six variables including bioclimatic variables, physiographic variables, NDVI, and anthropogenic factors were used.

\section{Species response curve}

After evaluating the models and finding the model with the highest efficiency, response curves of the species to the environmental variables were drawn, and relationships between the habitat suitability and the input variables were assessed. Response curve is an essential part of SDM and plots species presence data in relation to environmental variations. The range between the upper and lower boundaries of ecological conditions in the species' response curve is identified as the species ecological niche (Jongman et al., 1995; Gégout and Krizova, 2003).

\section{Results}

\section{Models accuracy assessment}

Table 2 compares the performance of the modelling under the scenarios. It is apparent from the table that achieved accuracy of the models were good to excellent. Among the employed modelling approaches under both scenarios, the ensemble modelling performed best with AUC values of 0.99. Among the individual models, GLM and MaxEnt had the best predictability based on accuracy statistics. However, CTA algorithm ranked the lowest with AUCs of 0.92 and 0.88 under scenarios I and II, respectively (Table 2).

Table 2. Accuracy statistics used to evaluate applied model's performance. Values are averages over 10 replicate runs

\begin{tabular}{c|c|c|c|c|c|c|c|c}
\hline \multicolumn{5}{c|}{ Scenario I } & \multicolumn{4}{c}{ Scenario II } \\
& TSS & AUC & Sensitivity & Specificity & TSS & AUC & Sensitivity & Specificity \\
\hline GLM & 0.94 & 0.97 & 100 & 93.64 & 0.92 & 0.97 & 98 & 94.32 \\
ANN & 0.92 & 0.96 & 100 & 92.48 & 0.83 & 0.92 & 93 & 90.08 \\
RF & 0.88 & 0.95 & 99 & 89.54 & 0.91 & 0.96 & 100 & 90.96 \\
CTA & 0.83 & 0.92 & 90 & 93.5 & 0.76 & 0.88 & 84 & 92.58 \\
MaxEnt & 0.94 & 0.97 & 100 & 93.64 & 0.93 & 0.97 & 100 & 92.62 \\
Ensemble & 0.96 & 0.99 & 100 & 96.35 & 0.98 & 0.99 & 100 & 98.05 \\
\hline
\end{tabular}

According to Table 2 mean accuracy under scenario I was higher when compared to under scenario II. These higher mean AUC ratios highlight the effectiveness of climatic variables for the prediction of species habitat. Analysis of the relative importance of environmental variables showed that under scenario I, Bio-04, Bio-03, Bio-08, Bio-14, 
and NDVI contributed most to the performance of our models with $31.58,27.35,21.97$, 17.15 , and 1.95 percent contribution, respectively (Table 3).

Table 3. Percent contribution of predictors under scenario I. Values shown are averages over 10 replicate runs

\begin{tabular}{c|c|c|c|c|c|c}
\hline & GLM & ANN & RF & CTA & MaxEnt & Ensemble \\
\hline Bio14 & 20.98 & 17.15 & 3.96 & 21.18 & 22.49 & 17.15 \\
Bio3 & 30.07 & 35.96 & 16.63 & 24.36 & 29.72 & 27.35 \\
Bio4 & 32.81 & 29 & 33.98 & 32.94 & 29.15 & 31.58 \\
Bio8 & 16.1 & 17.7 & 36.95 & 21.06 & 18.06 & 21.97 \\
NDVI & 0.04 & 0.19 & 8.48 & 0.46 & 0.58 & 1.95 \\
\hline
\end{tabular}

Under scenario II, Bio4 was the most impacting factor for species distribution with $22.43 \%$ contribution rate. The other four environmental factors affecting species distribution include distance to village (17.05\%), Bio3 (15.16\%), and Bio14 (10.6\%) (Table 4).

Table 4. Percent contribution of predictors under scenario II. Values shown are averages over 10 replicate runs

\begin{tabular}{c|c|c|c|c|c|c}
\hline & GLM & ANN & RF & CTA & MaxEnt & Ensemble \\
\hline Elevation & 2.28 & 12.82 & 14.88 & 0 & 3.4 & 6.67 \\
Aspect & 2.69 & 8.26 & 6.33 & 1.42 & 6.28 & 5 \\
Bio14 & 10.13 & 13.93 & 0.45 & 14.16 & 14.32 & 10.6 \\
Bio3 & 16.96 & 15.11 & 7.25 & 12.28 & 24.2 & 15.16 \\
Bio4 & 17.78 & 10.6 & 23.15 & 39.87 & 20.75 & 22.43 \\
Bio8 & 4.3 & 13.43 & 7.45 & 0 & 4.41 & 5.92 \\
NDVI & 1.47 & 0.13 & 9.11 & 0 & 1.08 & 2.36 \\
Distance to road & 8.34 & 7.73 & 6.59 & 6.49 & 1.56 & 6.14 \\
Slope & 1.08 & 2.8 & 6.58 & 0 & 2.64 & 2.62 \\
Distance to village & 20.68 & 8.64 & 13.09 & 25.78 & 17.08 & 17.05 \\
Distance to river & 14.29 & 6.55 & 5.12 & 0 & 4.28 & 6.05 \\
\hline
\end{tabular}

\section{Species distribution by different scenarios}

The habitat suitability map indicated that a vast region within the study area has low suitability for brown bear. The species suitable habitats were distributed along the Zagros oak-dominated forests where because of higher altitude weather is characterized by a higher precipitation than the whole region's mean values. Spatial distribution of brown bear projected by the models and under scenarios I and II are displayed in Figure 3 and Figure 4, respectively. It is apparent from Figure 2 that different models even with nearly equal AUC value projects the habitat suitability and potential habitats differently.

Among the climatic factors, under both scenarios Bio-04, Bio-03, and Bio-14 variables were recognized as the most influential parameters in the modelling process. The species' response curves to the most important predictors are shown in Figure 4.

Bio3 (Isothermality) quantifies how extensively the day-to-night temperatures oscillate relative to the summer-to-winter (annual) oscillations. 


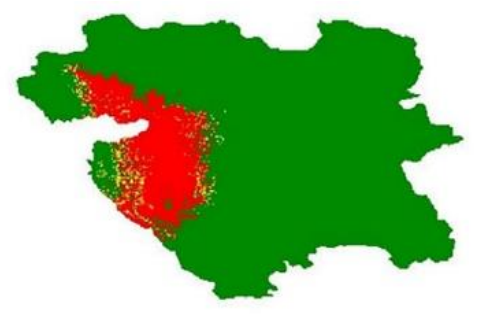

GLM

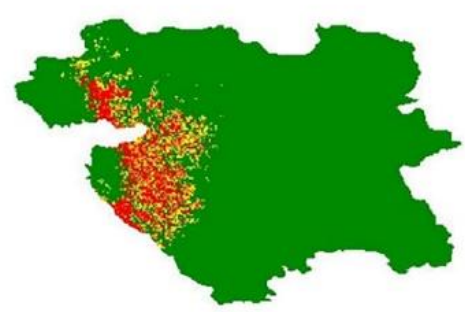

RF

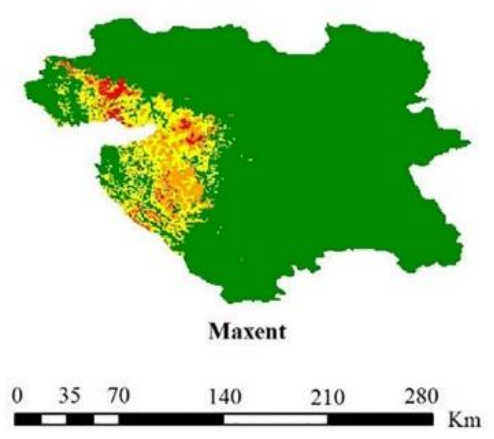

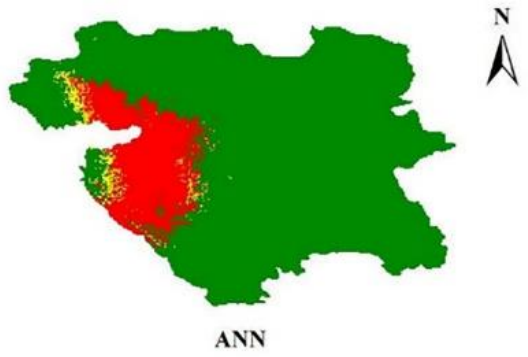

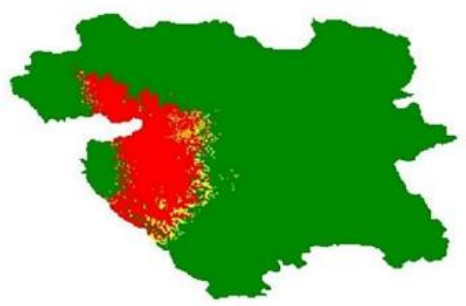

CTA

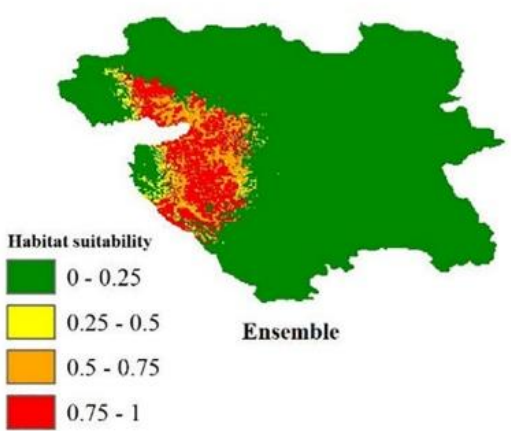

Figure 3. Potential distribution maps for brown bear modelled using GLM, ANN, RF, CTA, MaxEnt, and Ensemble under scenario I. Values range from 0 to 1 where 0 represent sites with the lowest suitability and 1 represent sites with the highest suitability

According to the related response curve, brown bear shows a preference for regions with isothermality of less than 34 and habitat suitability was lowest when it is higher than 37. In other words, the species prefers smaller level of temperature variability within an average month relative to the year.

Bio4 is defined as the amount of temperature variation over a given year (or averaged years) based on the standard deviation (variation) of monthly temperature averages. According to the species response curve to this variable, maximum habitat suitability was observed when temperature seasonality is higher than 9500. Further, a positive relationship was observed between occurrence records and the variable so that the probability of brown bear presence increases as the temperature seasonality increases.

Bio14 is defined as the total precipitation in the driest month. As the curve shows this variable is negatively correlated with distribution of the species. The maximum presence of the species occurs in regions where precipitation of the driest month is lower than 0.5 $\mathrm{mm}$ and habitat suitability drastically decreases and then stabilizes as the precipitation of driest month rises. Response curve of brown bear to distance to villages indicates that a high probability of occurrence of this species is in proximity to villages (Fig. 5). 


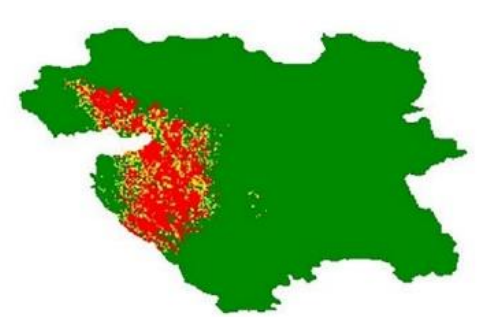

GLM

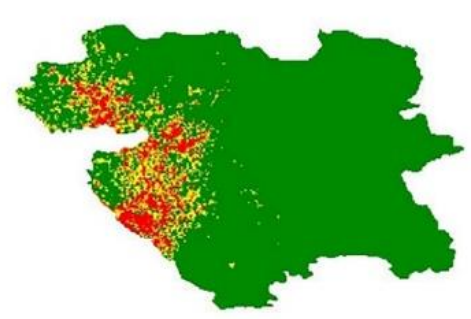

RF

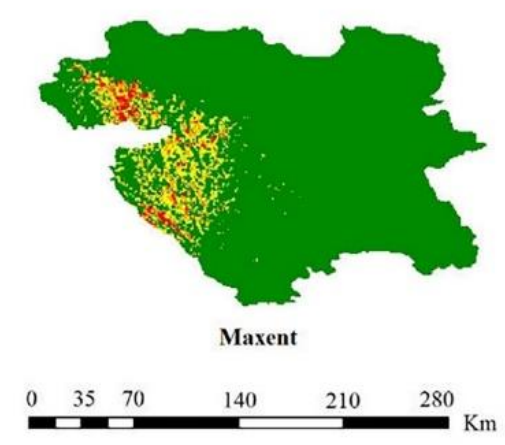

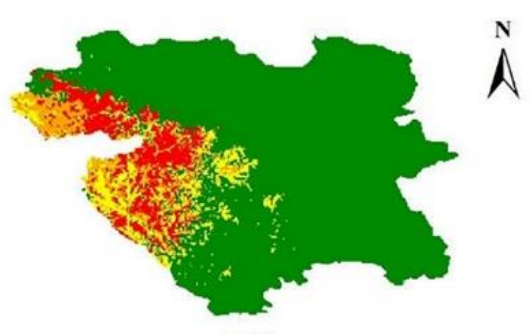

ANN

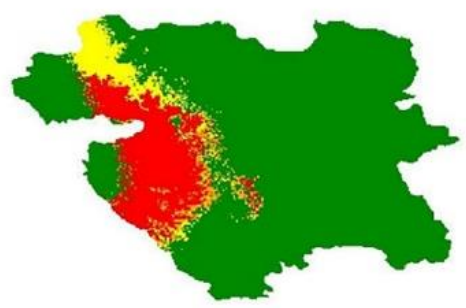

CTA

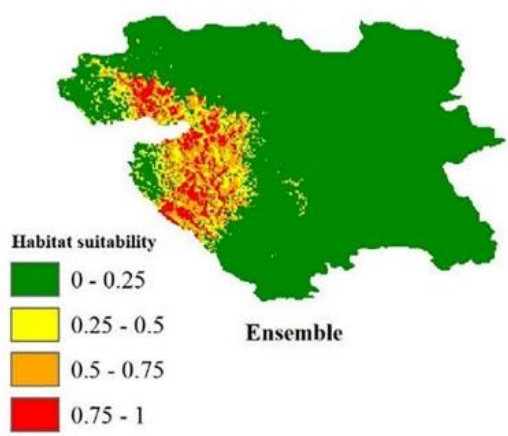

Figure 4. Potential distribution maps for brown bear modelled using GLM, ANN, RF, CTA, MaxEnt, and Ensemble under scenario II. Values range from 0 to 1 where 0 represents the sites with the lowest suitability and 1 represents the sites with the highest suitability

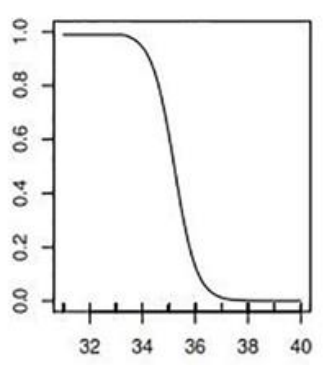

Bio3

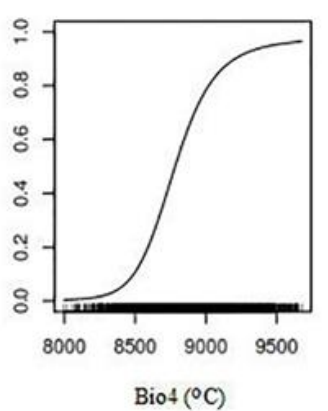

$\mathrm{Bio} 4\left({ }^{\circ} \mathrm{C}\right)$

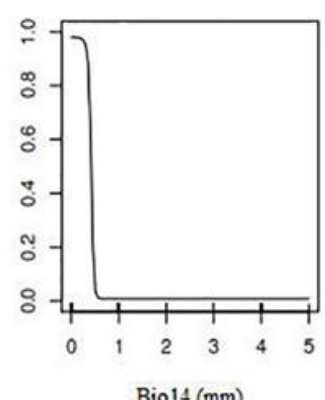

Bio14 (mm)

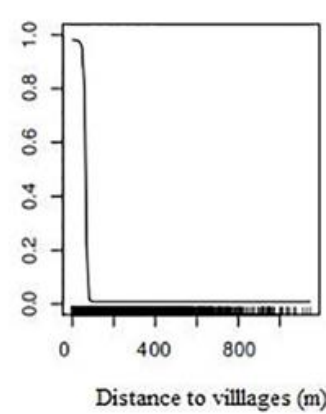

Figure 5. Relationships between environmental predictor variables and the probability of presence of brown bear in Kurdistan, Iran. Vertical axis exhibits the projected values of habitat suitability, and horizontal axis exhibits the value of environmental factor 


\section{Discussion}

In this study modelling potential sites for brown bear in Kurdistan Province was performed using five different algorithms and performance of the algorithms was compared with each other. This kind of comparison enables us to find and take advantage of the most efficient methods that can provide more accurate and credible results. We found that different algorithms despite of having the same AUC value projected the potential habitat differently. Amiri et al. (2020) also have confirmed the point of view that the accuracy of projections could be fundamentally different among SDMs. In this matter, the ensemble approach revealed the lowest error to delineate suitable habitat of the species in the regions which is in line with results of Shabani et al. (2016). After the ensemble approach, GLM and MaxEnt had the most accurate performance. A study conducted by Shabani et al. (2016) showed similarly that GLM and MaxEnt among five modelling algorithms had the most accurate performance. The reason could be explained by the fact that MaxEnt works based on presence-background data instead of presenceabsence data and most importantly, does not presume that background data precludes the probability of occurrence (Evangelista et al., 2008). CTA was recognized as the model with the weakest predictability, which is in line with the result of Marmion et al. (2009).

Response curves of the species to the variables as well as the relationship between predictor variables and habitat suitability were obtained based on observations in the study area. In our study bioclimatic variables found to be more important in the species distribution when compared to physiographic parameters. Hemami et al. (2015), also introduced climatic parameters as the most effective determinants in distribution of brown bear. We found that isothermality, temperature seasonality, and precipitation of driest month variables may challenge the distribution of brown bear by potential effects. These effects are predicted to trigger shifts in the species distribution and threatening its viability due to habitat loss (Parmesan, 2006).

It could be understood from the response curve of the species to precipitation of driest month that brown bear could be observed more frequently during the dry period. Precipitation and availability of water are essential for brown bear as low precipitation leads to changes in plant community and biomass in the following months. One reason may be that brown bear become more visible during the driest month first because of less vegetation and the fact that they have to move around to find higher quality habitats ( $\mathrm{Su}$ et al., 2018). Another reason could be that the dry period leads to a concentration in the brown bear population in response to lack of water. Doan-Crider et al. (2017) stated that in dry periods occurrence frequency of black bear (Ursus americanus) and the concentration of this species around water sources increases.

We also investigated the effect of anthropogenic disturbance on habitat suitability by employing distance to village variable in the modelling. Kouchali et al. (2019) modelled spatial distribution of brown bear in Alborz Forests and concluded that suitability of habitat decreases with increasing distance to village that is in line with results of present study. However, Almasieh et al. (2019) modelled habitat suitability for brown bear in the northern Zagros Forests along the Iran-Iraq border and found that there is a direct relationship between the probability of presence and distance from village which is against results of present study. The reason could be because of employing higher number of the occurrence records in or around the villages in the current study due to higher sampling density closer to villages. This emphasizes the importance of even sampling effort across the study area. Previous studies provided many reasons for higher bear presence in proximity to humans such as (1) naive behavior or lack of experience in young 
brown bears with people (Kaczensky et al., 2006), (2) high mobility of the species in combination with its nocturnal activity peaks (Mueller et al., 2004), and, (3) because of the high-quality and high-calorie foods that are provided by humans. Despite wildland foods being available, bears may prefer garbage, fruit trees in orchards, honey, and field crops as high-quality and high-calorie food sources available in and around villages (Fahimi et al., 2018).

Originally brown bears avoid humans (Støen et al., 2015); but due to forest degradation, climate and land cover change and consequently habitat loss, natural food sources for brown bear may become insufficient and lead to incidence of this species moving to anthropogenic areas in search of foods like garbage, fruit trees, livestock, and bee yards (Rodriguez et al., 2007; Yousefi, 2016). Any loss of habitat especially within protected areas may result in brown bears moving out of the protected habitat or illegal hunting area and encounter with human. So it is vital to upgrade distribution of protected habitats to enhance species conservation under climate change (Hannah et al., 2007). Large scale forest and habitat degradation in the Zagros Forests during the last decades is shown in different studies as following. Henareh-Khalyani et al. (2014) found that because of unemployment and poverty in a part of the northern Zagros Forests in Kurdistan Province people overexploited the forests which led to a decrease in area of productive and arable lands. Other studies also showed that forest area in Kurdistan Province decreased recently mainly because of agricultural and residential expansion (Yousefi et al., 2011), and habitats of other species like Persian squirrel (Sciurus anomalus) have been lost (Sadeghi, 2014). Anthropogenic pressure in human-modified landscapes may intensify negative impacts of climate change (Maiorano et al., 2011). Henareh-Khalyani et al. (2013) revealed that climate change and population growth in urbans are main causes of the Zagros Forests degradation. Aryal (2011) showed that food availability did affect the home range of Asiatic black bears (Ursus thibetanus). This has resulted in increasing human-bear coexistence and finally a higher probability of humanbear conflicts and bear mortalities. Gutleb and Ziaie (1999) emphasized on the importance of management plans to mitigate such conflicts in the Zagros Forests. Several studies conducted on black bear in the south of Iran showed that in response to habitat degradation and scarcity of natural foods human-bear conflicts have increased and black bears have been frequently killed by locals (Gutleb and Ziaie, 1999; Ghadirian et al., 2017). A similar increase in human-bear conflict has been reported in North America after the reduction of white bark pine (Pinus albicaulis) forests on which grizzly bear relied particularly after mast seed production (Schrag et al., 2008). Degradation and destruction of forests makes them a less secure habitat and thus leaves brown bears more exposed to hunters.

\section{Conclusion}

The Zagros Forests are currently considered as rapidly changing and being degraded forests. Oak trees are slow growing plants and take decades to mature making oak forests susceptible to destruction. In the study area, local people are strongly depending on forests and recently anthropogenic disturbances have adversely affected habitat suitability for low-density brown bear making environmental studies necessary for the conservation of this species. In the present study, we found that brown bear distribution is attributed to bioclimatic variables representing impact of future meteorological conditions on this species habitat. Distance to village variable proved to be a key anthropogenic parameter 
in the distribution of the species and indicated that a major portion of brown bear populations overlap with residential areas resulting in human-bear conflicts. Further land use change and forest destruction especially due to the development of gardens, agricultural lands, and residential areas, as well as climate change would increase this conflict in the future. This conflict raises conservation concerns and magnifies the importance of habitat conservation programs and also human-bear conflict management plans. These plans should include helping local communities to reduce or compensate economic losses caused by brown bear as well as enhancing people's awareness. Eventually, large-scale conservation efforts and further studies in the Zagros region should be performed to ensure the long-term viability of brown bear and to protect habitats that can support a whole range of species, of which some may be threatened but less in focus of conservation actions.

\section{REFERENCES}

[1] Allouche, O., Tsoar, A., Kadmon, R. (2006): Assessing the accuracy of species distribution models: prevalence, kappa, and the true skill statistics (TSS). - Journal of Applied Ecology 43: 1223-1232.

[2] Almasieh, K., Rouhi, H., Kaboodvandpour, S. (2019): Habitat suitability and connectivity for the brown bear (Ursus arctos) along the Iran-Iraq border. - European Journal of Wildlife Research 65(4).

[3] Amiri, M., Tarkesh Esfahani, M., Jafari, R., Jetschke, G. (2020): Bioclimatic variables from precipitation and temperature records vs. remote sensing-based bioclimatic variables: which side can perform better in species distribution modeling? - Ecological informatics 57: 101060 .

[4] Araújo, M. B., New, M. (2007): Ensemble forecasting of species distributions. - Trends in Ecology and Evolution 22: 42-46.

[5] Araújo, M. B., Alagador, D., Cabeza, M., Nogués-Bravo, D., Thuiller, W. (2011): Climate change threatens European conservation areas. - Ecology Letters 14: 484-492.

[6] Arsalani, M., Azizi, G., Bräuning, A. (2015): Dendroclimatic reconstruction of May-June maximum temperatures in the central Zagros Mountains, western Iran. - International Journal of Climatology 35(3): 408-416.

[7] Aryal, A. (2011): Cultural and Religious Beliefs Pose Challenges for Bear Conservation in Nepal. - International Bear News 20(1): 12-14.

[8] Beier, P., Majka, D., Spencer, W. D. (2008): Forks in the road: choices in procedures for designing wildland linkages. - Conservation Biology 22(4): 836-851.

[9] Berry, P. M., Dawson, T. P., Harrison, P. A., Pearson, R. G. (2002): Modelling potential impacts of climate change on the bioclimatic envelope of species in Britain and Ireland. Global Ecology and Biogeography 11: 453-462.

[10] Breiman, L. (2001): Random forests. - Machine Learning 45: 5-32.

[11] Breiman, L., Friedman, J., Stone, C. J., Olshen, R. A. (1984): Classification and regression trees. - Chapman and Hall/CRC press, London.

[12] Buisson, L., Thuiller, W., Casajus, N., Lek, S., Grenouillet, G. (2010): Uncertainty in ensemble forecasting of species distribution. - Global Change Biology 16: 1145-1157.

[13] Can, Ö. E., Cruze, N. D., Garshelis, D. L., Beecham, J. J., Macdonald, D. W. (2014): Resolving human-bear conflict: a global survey of countries, experts and key factors. Conservation Letters 7: 501-513.

[14] De'Ath, G. (2007): Boosted trees for ecological modeling and prediction. - Ecology Letters 88: 243-251.

[15] Department of Environment (2014): Conservation of biodiversity in the central Zagros landscape conservation zone. Zagros project office. - Zagros project office. Tehran, Iran. 
[16] Doan-Crider, D. L., Tri, A. N., Hewitt, D. G. (2017): Woody cover and proximity to water increase American black bear depredation on cattle in Coahuila, Mexico. - Ursus 28(2): 208-217.

[17] Elith, J., Leathwick, J. R. (2009): Species distribution models: ecological explanation and prediction across space and time. - Annual Review of Ecology, Evolution, and Systematics 40: 677-697.

[18] Evangelista, P. H., Kumar, S., Stohlgren, T. J., Jarnevich, C. S., Crall, A. W., Norman, J. B., Barnet, D. T. (2008): Modelling invasion for a habitat generalist and a specialist plant species. - Diversity and Distributions 14(5): 808-817.

[19] Fahimi, H., Qashqaei, A. T., Chalani, M., Asadi, Z., Broomand, S., Ahmadi, N., Yusefi, G. H. (2018): Evidence of seed germination in scats of the Asiatic Black Bear (Ursus thibetanus) in Iran (Mammalia: Carnivora). - Zoology in the Middle East 64(2): 182-184.

[20] Gallo, C. (2015): Artificial neural networks tutorial. - Encyclopedia of information science and technology: third edition, pp. 179-189.

[21] Gégout, J.-C., Krizova, E. (2003): Comparison of indicator values of forest understory plant species in Western Carpathians (Slovakia) and Vosges Mountains (France). - Forest Ecology and Management 182: 1-11.

[22] Ghadirian, T., Qashqaei, A. T., Soofi, M., Abolghasemi, H., Ghoddousi, A. (2017): Diet of Asiatic black bear in its westernmost distribution range, southern Iran. - Ursus 28: 15-19.

[23] Ghazanfari, H. (2003): Evaluation of growth and changes in diameter distribution of Quercus libani and Quercus infectoria stands to present forest adjustment pattern in Baneh region (Case study: Hawarakhol). - PhD Thesis. University of Tehran, Iran. (In Persian).

[24] Gutleb, B., Ziaie, H. (1999): On the distribution of the Brown Bear, (Ursus arctos), \& the Asiatic Black Bear, (Ursus thibetanus), in Iran. - Zoology in the Middle East 18(1): 5-8.

[25] Gutleb, B., Ghaemi, R. A., Kusak, J. (2002): Brown bear in Iran. - International bear news 11-20.

[26] Hanafi, A., Hatammi, I. (2013): Producing climate map for Kurdistan Province using information technology system. - Scientific-research quarterly of geographical data (SEPEHR) 22(87): 24-28. (In Persian).

[27] Hannah, L., Midgley, G., Andelman, S., Araujo, M., Hughes, G., Martinez-Meyer, E., Pearson, R., Williams, P. (2007): Protected area needs in a changing climate. - Frontiers in Ecology and the Environment 5: 131-138.

[28] Hemami, M. R., Esmaeili, S., Soffianian, A. R. (2015): Predicting the Distribution of Asiatic Cheetah, Persian Leopard and Brown Bear in Response to Environmental Factors in Isfahan Province. - Iranian Journal of Applied Ecology 4(13): 51-64.

[29] Henareh Kalyani, A., Mayer, A. L., Falkowski, M. J., Muralidharan, D. (2013): Deforestation and landscape structure changes related to socioeconomic dynamics and climate change in Zagros forests. - Journal of Land Use Science 8: 321-340.

[30] Henareh Khalyani, J., Namiranian, M., Heshmatol Vaezin, S. M., Feghhi, J. (2014): Development and evaluation of local communities incentive programs for improving the traditional forest management: A case study of Northern Zagros forests, Iran. - Journal of Forestry Research 25: 205-210.

[31] Hoekstra, T. W., Shachak, M. (1999): Arid Lands Management: Toward Ecological Sustainability. - Urbana University of Illinois Press.

[32] Hosmer, D. W., Lemeshow, S. (2000): Applied Logistic Regression. - Wiley, New York.

[33] Hwang, M. H., Garshelis, D. L., Wu, Y. H., Wang, Y. (2010): Home ranges of Asiatic black bears in the Central Mountains of Taiwan: Gauging whether a reserve is big enough. - Ursus 21(1): 81-96.

[34] Jazirehi, M. H., Rostaghi, E. M. (2003): Silviculture in Zagros. - University of Tehran Press, Tehran.

[35] Jongman, R. H. G., Ter Break, C. J. F., Van Tongeren, O. F. R. (1995): Data analysis in community and landscape ecology (2th edition). - Cambridge University Press, Cambridge. 
[36] Kaczensky, P., Huber, D., Knauer, F., Roth, H., Wagner, A., Kusak, J. (2006): Activity patterns of brown bears (Ursus arctos) in Slovenia and Croatia. - Journal of Zoology 269(4): 474-485.

[37] Kindt, R. (2018): Ensemble species distribution modelling with transformed suitability values. - Environmental Modelling and Software 100: 136-145.

[38] Kobler, A., Adamic, M. (2000): Identifying brown bear habitat by a combined GIS and machine learning method. - Ecological Modelling 135: 291-300.

[39] Kouchali, F., Nezami, B., Goshtasb, H., Rayegani, B., Ramezani, J. (2019): Brown Bear (Ursus arctos) habitat suitability modelling in the Alborz Mountains. - Internaional Journal of Environmenal Science and Bioengineering 12: 45-54.

[40] Maiorano, L., Falcucci, A., Zimmermann, N. E., Psomas, A., Pottier, J., Baisero, D., Rondinini, C., Guisan, A., Boitani, L. (2011): The future of terrestrial mammals in the mediterranean basin under climate change. - Philosophical Transactions of the Royal Society B: Biological Sciences 366: 2681-2692.

[41] Marmion, M., Luoto, M., Heikkinen, R. K., Thuiller, W. (2009): The performance of stateof-the-art modelling techniques depends on geographical distribution of species. Ecological Modeling 220: 3512-3520.

[42] McCullagh, P., Nelder, J. A. (1989): Generalized Linear Models. - Chapman and Hall, London.

[43] McLellan, B. N., Proctor, M. F., Huber, D., Michel, S. (IUCN SSC Bear Specialist Group). (2016): Brown bear (Ursus arctos) isolated populations (supplementary material to Ursus arctos redlisting account). - The IUCN red list of threatened species.

[44] Mirabolfathy, M., Groenewald, J. Z., Crous, P. W. (2011): The occurrence of characoal disease caused by Biscogniauxia mediterranea on chestnut-leaved oak (Quercus castaneifolia) in the Golestan Forests of Iran. - Plant Disease 95: 876.

[45] Moraitis, M. L., Valavanis, V. D., Karakassis, I. (2019): Modelling the effects of climate change on the distribution of benthic indicator species in the Eastern Mediterranean Sea. Science of the Total Environment 667: 16-24.

[46] Mueller, C., Herrero, S., Gibeau, M. L. (2004): Distribution of subadult grizzly bears in relation to human development in the Bow River Watershed, Alberta. - Ursus 15: 35-47.

[47] Parmesan, C. (2006): Ecological and evolutionary responses to recent climate change. Annual Review of Ecology, Evolution, and Systematics 37: 637-669.

[48] Phillips, S. J., Anderson, R. P., Schapire, R. E. (2006): Maximum entropy modeling of species geographic distributions. - Ecological Modeling 190: 231-259.

[49] Phillips, S. J., Dudík, M., Elith, J., Graham, C. H., Lehmann, A., Leathwick, J., Ferrier, S. (2009): Sample selection bias and presence-only distribution models: Implications for background and pseudo-absence data. - Ecological Applications 19: 181-197.

[50] Porfirio, L. L., Harris, R. M. B., Leofroy, E. C., Hugh, S., Gould, S. F., Lee, G., Bindoff, N. L., Mackey, B. (2014): Improving the use of species distribution models in conservation planning and management under climate change. - PLoS ONE 9(11): e113749.

[51] Ray, D., Behera, M. D., Jacob, J. (2016): Predicting the distribution of rubber trees (Hevea brasiliensis) through ecological niche modeling with climate, soil, topography and socioeconomic factors. - Ecological Research 31: 75-91.

[52] Rodriguez, C., Naves, J., Fernandez-Gil, A., Obeso, J. R., Delibes, M. (2007): Long-term trends in food habitats of a relict brown bear population in northern Spain: The influence of climate and local factors. - Environmental Conservation 34: 36-44.

[53] Sadeghi, M. (2014): Habitat change detection of Persian squirrel (Sciurus anomalus) in Kurdistan province. - MSc Thesis. Isfahan University of Technology, Iran. (In Persian).

[54] Sagheb-Talebi, Kh., Sajedi, T., Yazdian, F. (2003): Forests of Iran, Tehran. - Research Institute of Forests and Rangelands of Iran: 56. (In Persian).

[55] Schrag, A. M., Bunn, A. G., Graumlich, L. J. (2008): Influence of bioclimatic variables on tree-line conifer distribution in the Greater Yellowstone Ecosystem: Implications for species of conservation concern. - Journal of Biogeography 35: 698-710. 
[56] Shabani, F., Kumar, L., Ahmadi, M. (2016): A comparison of absolute performance of different correlative and mechanistic species distribution models in an independent area. Ecology and Evolution 6(16): 5973-5986.

[57] Sharifi, M., Hadidi, M., Vessali, E., Mosstafakhani, P., Taheri, K., Shahoie, S., Khodamoradpour, M. (2009): Integrating multi-criteria decision analysis for a GIS-based hazardous waste landfill sitting in Kurdistan Province, western Iran. - Waste Management 29: $2740-2758$.

[58] Støen, O. G., Ordiz, A., Evans, A. L., Laske, T. G., Kindberg, J., Fröbert, O., Swenson, J. E., Arnemo, J. M. (2015): Physiological evidence for a human-induced landscape of fear in brown bears (Ursus arctos). - Physiology and Behavior 152: 244-248.

[59] Su, J., Aryal, A., Hegab, I. M., Shrestha, U. B., Coogan, S. C. P., Sathyakumar, S., Dalannast, M., Dou, Z., Suo, Y., Dabu, X., Fu, H., Wu, L., Ji, W. (2018): Decreasing brown bear (Ursus arctos) habitat due to climate change in Central Asia and the Asian Highlands. - Ecology and Evolution 8(23): 11887-11899.

[60] Swenson, J. E., Dahle, B., Gerstl, N., Zedrosser, A. (2000): Action Plan for the conservation of the Brown Bear (Ursus arctos) in Europe, Conventiononthe Conservation of European Wildlife and Natural Habitats (Bern Convention). - Nature and Environment 114. Council of Europe Publishing, Strasbourgh, France.

[61] Swets, J. (1988): Measuring the accuracy of diagnostic systems. - Science 240: 1285-1293.

[62] Thuiller, W., Araújo, M. B., Lavorel, S. (2003): Generalized models vs classification tree analysis: predicting spatial distributions of plant species at different scales. - Journal of Vegetation Science 14: 669-680.

[63] Thuiller, W., Lafourcade, B., Engler, R., Araújo, M. B. (2009): BIOMOD - A platform for ensemble forecasting of species distributions. - Ecography 32: 369-373.

[64] Treves, A., Naughton-treves, L., Mladenoff, D. J., Harper, E. K., Mladenoff, D. J., Rose, R. A., Sickley, T. A., Wydeven, A. P. (2004): Predicting human carnivore conflict: a spatial model derived from 25 years of data on wolf predation on livestock. - Conservation Biology 18: 114-125.

[65] Tripathi, B. K. (2015): High Dimensional Neurocomputing - Growth, Appraisal and Applications. - Springer, Germany.

[66] United States Geological Survey (2020): Earthexplorer. - Available at: http://www.earthexplorer.usgs.gov (accessed: 28 November 2020).

[67] Velez-Liendo, X., Strubbe, D., Matthysen, E. (2013): Effects of variable selection on modelling habitat and potential distribution of the Andean bear in Bolivia. - Ursus 24(2): 127-138.

[68] Wang, B., Deverson, E. D., Waters, C., Spessa, A., Lawton, D., Feng, P. Y., Liu, D. L. (2019): Future climate change likely to reduce the Australian plague locust (Chortoicetes terminifera) seasonal outbreaks. - Science of the Total Environment 668: 947-957.

[69] Welch, C. A., Keay, J., Kendall, K. C., Robbins, C. T. (1997): Constraints on frugivory by bears. - Ecology 78: 1105-1119.

[70] Willson, M., Gende, S. (2004): Seed Dispersal by Brown Bears, (Ursus arctos), in Southeastern Alaska. - The Canadian Field-Naturalist 118(4): 499-503.

[71] Worldclim (2019): Global Climate Data, Version 2 (Free climate data for ecological modeling and GIS). - http://worldclim.org/version2 (accessed 08.02.2020).

[72] Yi, Y. J., Cheng, X., Yang, Z. F., Zhang, S. H. (2016): Maxent modelling for predicting the potential distribution of endangered medicinal plant (H. riparia Lour) in Yunnan, China. - Ecological Engineering 92: 260-269.

[73] Yousefi, G. (2016): Strategic plan for brown bear (Ursos arctos) conservation in Iran. Department of Environment, Iran, Tehran. (In Persian).

[74] Yousefi, S., Moradi, H. R., Hosseini, S. H., Mirzaee, S. (2011): Land use change detection using Landsat TM and ETM+ satellite images over Marivan. - Journal of applied RS and GIS for natural resources 2(3): 97-105. 
[75] Zanin, M., Palomares, F., Brito, D. (2015): What we (don't) know about the effects of habitat loss and fragmentation on felids. - Oryx 49: 96-106.

[76] Ziaie, H. (2008): A field Guide to the Mammals of Iran. - Iranian wildlife center, Tehran, Iran. (In Persian). 